\title{
REVISTA
}

\section{PET NAS ESCOLAS: O CONHECIMENTO “PLURIVERSITÁRIO” PROMOVIDO PELO PET ECONOMIA DA UNIVERSIDADE ESTADUAL DO SUDOESTE DA BAHIA}

\section{RESUMO:}

Olga Hianni Portugal Vieira ${ }^{1}$,

Este trabalho objetiva apresentar a relação extramuros desenvolvida pelo PET Economia da UESB com o trabalho intitulado "PET nas Escolas" como uma forma de auxiliar o aluno prévestibulando com a escolha do curso de graduação. Com isso, espera-se contribuir para a redução dos problemas sociais, acadêmicos e econômicos relacionados à retenção/evasão de discentes no curso de Economia na UESB. O projeto consistiu em apresentar para estudantes do ensino médio de uma rede estadual de educação em Vitória da Conquista, o Centro Territorial de Educação Profissional- CETEP, as características do curso de Ciências Econômicas, de modo geral, e a particularidades do curso na UESB. Foram retratados na sala de aula o objeto do curso, o tempo de duração, o fluxograma e as áreas no mercado de trabalho do economista. Adotou-se como material a utilização de slides para apresentação das informações e o método para realizar tal apresentação foi a exposição oral por parte dos (das) bolsistas do Programa. Em seguida, houve espaço para a fala dos estudantes do CETEP e um bate papo com os expositores e o tutor do Programa. Ao finalizar o projeto, os (as) alunos (as) da instituição se mostraram satisfeitos (as) pelo conhecimento adquirido e aqueles (as) que tinham o curso de Economia dentro do seu leque de opções, relataram mais segurança para a escolha do curso.

Palavras-Chave: Escolas, Evasão, Extensão, PET, Retenção.

\begin{abstract}
:
This paper aims to present the extramural relationship developed by the UESB PET Economy with the work titled "PET in the Schools" as a way to help students pre-enroll with the graduation course. With this, it is hoped to contribute to the reduction of social, academic and economic problems related to student retention / avoidance in the Economics course at UESB. The project consisted of presenting to the high school students of a state education network in Vitoria da Conquista, the Territorial Center of Professional Education - CETEP, the characteristics of the course of Economic Sciences, in general, and the particularities of the course in the UESB. The course object, duration, flow chart and areas in the economist's labor market were portrayed in the classroom. The use of slides for presentation of information was adopted as material and the method to perform such presentation was oral presentation by the Program's scholars. Then there was space for the students' speech at CETEP and a chat with the exhibitors and the tutor of the Program. At the end of the project, the students of the institution were satisfied with the knowledge acquired and those who had the course of Economics within their range of options, reported more security for the choice of course.
\end{abstract}

${ }^{1}$ Graduanda em Ciências Econômicas pela Universidade Estadual do Sudoeste da Bahia. Bolsista do Programa de Educação Tutorial em Ciências Econômicas da UESB - PET Economia UESB. Email:olgahianni@ hotmail.com

${ }^{2}$ Graduando de Ciências Econômicas pela Universidade Estadual do Sudoeste da Bahia. Bolsista do Programa de Educação Tutorial em Ciências Econômicas da UESB - PET Economia UESB. Email: faique.ribeiro@ hotmail.com 


\section{REVISTA}

\section{EXTENSÃO E CIDADANIA}

Keywords: Evasion, Extension, PET, Retention, Schools. 


\section{REVISTA}

\section{INTRODUÇÃO}

A universidade do século XXI foi pensada para criar o conhecimento transdisciplinar, mantendo o diálogo e o aprendizado a partir, também, do que a sociedade oferece. Esta nova organização universitária muito se difere do conhecimento abordado no século $\mathrm{XX}$, quando os pesquisadores determinavam os problemas científicos a serem solucionados. Santos (2004) menciona esta transição do modo de produção científico do século XX para o XXI como a passagem do conhecimento universitário para o conhecimento pluriversitário. Nesta nova abordagem, a ciência e a sociedade estão extremamente relacionadas, e a extensão universitária, agora, não apenas leva o conhecimento para a comunidade, mas também o traz. É a relação extramuros designada por Santos que caracteriza a nova forma de pensar a extensão. Assim, "a sociedade deixa de ser um objecto das interpelações da ciência para ser ela própria sujeita de interpelações à ciência. " (SANTOS, 2004)

Ao pensar a extensão universitária como parte responsável pela troca mútua de experiências entre a sociedade e a comunidade acadêmica, o PET Economia da Universidade Estadual do Sudoeste da Bahia (UESB) realizou o chamado "PET nas Escolas", um projeto que visou retratar o curso de Ciências Econômicas para os alunos do ensino médio que estão se preparando para entrar na universidade. A atividade ocorreu no Centro Territorial de Educação Profissional- CETEP, uma rede estadual de educação no município de Vitória da Conquista. De forma mais específica, pretendeu-se apresentar o objeto do curso, o tempo de duração, o elenco de disciplinas que constitui a matriz curricular e o mercado de trabalho do economista. Além disso, buscou-se abordar as características mais expressivas do curso na UESB e da Ciência Econômica em si.

Com isso, entende-se que o projeto pode fornecer maiores condições para orientar, aumentar e qualificar a demanda pelo curso de Ciências Econômicas. Compreende-se que, quanto mais informados estiverem os estudantes sobre o que é o curso, como funciona o seu mercado de trabalho e as áreas de atuação, quais serão as disciplinas abordadas no decorrer da graduação, bem como as especificidades do curso 


\section{REVISTA}

da UESB, mais conscientes escolherão o que estudar. Essa escolha consciente, feita a partir da identificação do aluno com as temáticas a serem abordadas durante a graduação, diminui a incidência de frustração, retenção e evasão dos discentes das universidades. Assim, percebe-se os vários benefícios nessa atividade de extensão promovida pelo PET, pois, à medida que contempla os estudantes com tais informações, os auxilia em um momento decisivo de suas vidas, contribui para o curso de Economia da UESB, atraindo estudantes mais amantes dessa ciência e, por isso, com mais possibilidades de serem bons profissionais

Para alcançar os objetivos traçados, utilizou-se como metodologia a apresentação, pelos próprios bolsistas do Programa, das informações acerca do curso de Economia por meio de slides. A outra parte do projeto consistiu numa dinâmica com balões para falar sobre o mercado de trabalho do economista. Cada balão continha dentro setores que o economista trabalha. Todos os alunos jogaram para cima os balões e, após misturarem, cada estudante pegou um balão. Ao estourá-lo, lia sobre a área profissional e os bolsistas e o tutor explicavam sobre o tema retirado do balão. Além disso, houve a promoção da participação dos petianos, do tutor e dos estudantes com momentos destinados à fala individual e com espaços para questionamentos. Sendo que, no início da apresentação, foram distribuídas folhas em branco a todos para que escrevessem e desenhassem sobre a ideia prévia que faziam de Economia. Ao final, as ideias sobre o antes e o depois foram contrastadas.

\section{RESULTADOS E DISCUSSÕES}

A universidade tem como objetivo formar cidadãos conscientes e aptos a contribuírem para melhoria da sociedade nas mais diversas áreas. Para tanto, faz-se necessário que sua sustentação esteja baseada no tripé acadêmico: Ensino, Pesquisa e Extensão. Este fundamento, presente na noção de ensino de qualidade, é garantido pela Constituição Federal Brasileira, que em seu artigo 207 diz “as universidades gozam de autonomia didático-científica, administrativa e de gestão financeira e patrimonial, e obedecerão ao princípio de indissociabilidade entre ensino, pesquisa e extensão" (BRASIL, 1988). Para Santos (2004), a universidade apenas existe se houver o ensino - 


\section{REVISTA}

formação graduada e pós-graduada - pesquisa e extensão. Sem esse tripé, o que existe é ensino superior, não universidade.

É neste contexto que a prática da Extensão, vista até o século passado como uma relação de mão única entre universidade e sociedade, se revela, nos dias atuais, como atividade emancipadora, pois exerce a função social de aproximar a comunidade acadêmica da sociedade, permitindo que o inverso aconteça. Ou seja, a relação exclusiva entre o sujeito e objeto é substituída pela reciprocidade entre o conhecimento científico e o conhecimento popular. Desta forma, a Lei de Diretrizes e Bases da Educação Nacional (LDB) de 1996 enumera o escopo da educação superior, determinando em seu artigo 43, inciso VII, a participação da população na promoção da extensão universitária: "promover a extensão, aberta à participação da população, visando à difusão das conquistas e benefícios resultantes da criação cultural e da pesquisa científica e tecnológica geradas na instituição”.

Entendido como modelo para uma educação pública de qualidade, os Programas de Educação Tutorial (PETs) promovem nas universidades o que elas, por si, não conseguem fornecer aos discentes por completo. Esta complementação, fortemente baseada na indissociabilidade entre ensino, pesquisa e extensão, cria e recria o processo Ensino-Aprendizagem entre a sociedade e universidade. Assim, de forma a contemplar o conhecimento pluriversitário, adquirido através das atividades emancipadoras da universidade extramuros, o PET Economia da Universidade Estadual do Sudoeste da Bahia promoveu o PET nas escolas, um projeto de extensão que levou aos alunos prévestibulandos do Centro Territorial de Educação Profissional- CETEP uma dinâmica educativa a fim de que conhecessem sobre o objeto do curso de Ciências Econômicas, tempo de duração, as disciplinas que constituem a sua matriz curricular, além das possíveis atuações no mercado de trabalho.

Em contrapartida, os alunos tiveram a oportunidade de escrever e falar o que pensavam sobre o curso, antes e depois da apresentação dos slides. Desse modo, pôdese perceber qual a visão que os estudantes tinham do curso de economia e contrapô-la com a realidade, de modo a guiá-los a fazer uma escolha de curso mais consciente. Com isso, a atividade não só levou o conhecimento ao público-alvo, como também trouxe 


\section{REVISTA}

conhecimento para a universidade.

O PET nas escolas, por meio do diálogo direto com a sociedade, permite que a universidade e a comunidade sejam amplamente beneficiadas, pois contribui para a diminuição da retenção e evasão de discentes nos cursos. Entende-se por evasão o número de discentes regulares que abandonam seus cursos, enquanto que a retenção é associada à ultrapassagem do tempo de integralização curricular previsto. Ambos os fatores podem ser associados ao ingresso inconsciente do aluno, que, ao desconhecer sobre o objeto do curso e a dinâmica do mercado de trabalho, não se sentem contemplados com o que é estudado no decorrer da graduação.

O curso de Ciências Econômicas da UESB situa-se no campus de Vitória da Conquista e foi fundado em 1998. Os problemas institucionais relacionados à evasão e retenção de discentes no curso provocam problemas sociais, acadêmicos e econômicos. Da data de fundação até a última turma que concluiu a graduação, verificou-se que o curso apresentou cerca de $40 \%$ de evasão/retenção discente. Em outras palavras, a cada dez alunos que ingressam, aproximadamente 6 colam grau no tempo mínimo previsto. Esta estatística dificulta o desenvolvimento do próprio curso, visto que o investimento feito para acolher, anualmente, 40 alunos apenas serve para atender a 16 alunos em média. Além disso, retira dos discentes que escolheram, conscientemente, o curso de Economia, mas não conseguiram passar no exame vestibular, uma chance de ingresso na universidade. Outro importante aspecto é a frustração do discente que desiste ou fica retido no curso.

Tal problema pode refletir duas realidades: Uma relacionada a fatores internos, como motivos pessoais dos discentes e outra atrelada a fatores externos, como a proposta pedagógica apresentada pelo curso ou a expectativa de mercado de trabalho. Com base nesse segundo fator, o PET Economia da UESB emoldurou o projeto que viria a se chamar PET nas Escolas, uma tentativa de reduzir a evasão/retenção de discentes no curso de Economia por meio da qualificação dos discentes. Em outras palavras, pela oferta de informações para tornar a escolha do pré-vestibulando mais consciente.

Assim, a partir do conhecimento dos dados apresentados é que se justificou a 


\section{REVISTA}

ação do PET economia UESB no CETEP. O programa entende que, se o aluno escolher o curso dada as suas características como ciência e o seu mercado de trabalho, o ingresso deste na universidade pode ser mais proveitoso, visto que a incidência de frustração das expectativas diminuirá.

A portaria $\mathrm{n}^{\circ} 976$ do PET mostra os objetivos do Programa dentro das Universidades. Dentro desse escopo, pode-se vincular ao PET nas escolas:

- Desenvolver atividades acadêmicas em padrões de qualidade de excelência, mediante grupos de aprendizagem tutorial de natureza coletiva e interdisciplinar;

- Contribuir para a elevação da qualidade da formação acadêmica dos alunos de graduação;

- Estimular a formação de profissionais e docentes de elevada qualificação técnica, científica, tecnológica e acadêmica;

- Contribuir para a consolidação e difusão da educação tutorial como prática de formação na graduação;

- Contribuir com a política de diversidade na instituição de ensino superior- IES, por meio de ações afirmativas em defesa da equidade socioeconômica, étnico-racial e de gênero.

Verifica-se que, ao de cumprir com importantes disposições legais atribuídas ao PET na área que confere a extensão universitária, o projeto pôde produzir na sociedade efeitos em termos acadêmicos e econômicos. Ao analisar a extensão pela ótica emancipatória de Santos (2004), entende-se como ocorre essa interface entre o mercado de trabalho, a universidade e a sociedade. O projeto, que buscou contribuir com a retenção e evasão de discentes, também auxiliou o discente a dirimir suas dúvidas quanto ao mercado de trabalho. Esta relação "extramuros", com, pode-se dizer, práticas pedagógicas inovadoras, potencializa a ação extensionista e abre espaço para a democratização da Universidade, isto é, fazer-se mais acessível o conteúdo e o conhecimento produzido dentro da academia.

Sobre os aspectos metodológicos do projeto, Santos (2004) contribui ao relatar a dinamicidade contida na relação contraditória entre o conhecimento produzido na academia e o conhecimento pluriversitário, sendo importantes fatores de formação 


\section{REVISTA}

cidadã, profissional, crítica e reflexiva. Em tempos em que a autonomia pedagógica e o conhecimento científico da Universidade dependem da disposição financeira do Estado, e este reduz seu compromisso político, deve-se ressaltar os resultados obtidos com as ações universitárias.

\section{CONCLUSÃO}

A universidade tem papel central na transformação da sociedade, sobretudo por considerá-la com parte fundamental na produção do conhecimento. Neste sentido, o projeto PET nas Escolas possibilitou a realização de uma importante função atribuída à universidade e, principalmente, ao PET, que diz respeito a um dos pés do tripé acadêmico: a Extensão.

A atividade permitiu, tanto aos estudantes fora das dependências da universidade, quanto aos petianos, a difusão do conhecimento, o exercício da pró atividade e da autonomia, seja na elaboração da atividade sob a orientação do tutor, na exposição das informações sobre o curso de Ciências Econômicas, seja no retorno dado pelos alunos sobre o entendimento que os mesmos tinham sobre a profissão.

A orientação dos estudantes pré-vestibulandos quanto ao objeto e aos objetivos do curso de Ciências Econômicas, além de ampliar o conhecimento sobre a área, também cria caminhos para escolhas mais conscientes na escolha do curso. Com isso, entende-se que o projeto contribui para a diminuição de casos de retenção e evasão, ou seja, quando uma parte dos discentes percebe que o curso escolhido, na verdade, não contempla o seu anseio e desiste ou não encontra mais motivação para prosseguir e desiste de alguma (s) disciplina(s).

Desta forma, constata-se que o projeto PET nas Escolas teve papel importante na consolidação dos objetivos na universidade, isto é, na estruturação de um conhecimento pluriversitário, que permite criar e manter relações mútuas de aprendizado entre o espaço acadêmico e a comunidade. 


\section{REFERÊNCIAS}

BRASIL. Constituição (1988).Constituição [da] República Federativa do Brasil. Brasília, DF: Senado Federal.

CASTRO, L.M.C. A universidade, a extensão universitária e a produção de conhecimentos emancipadores. In: REUNIÃO ANUAL DA ANPED, 27. Caxambu, 2004.

MOITA, F.M.G.S.C; ANDRADE, F.C.B. Ensino-pesquisa-extensão: um exercício de indissolubilidade na pós-graduação. Revista Brasileira de Educação, Rio de Janeiro, 2009, v. 14, n.41, p. 269-393, 2009.

SANTOS, B.S.A Universidade no Séc. XXI: Para uma Reforma Democrática e Emancipatória da Universidade. São Paulo: Cortez Editora, 2004

Data de recebimento: 09/08/2017

Data de aprovação: 15/03/2018 